\title{
The Effects of Knee Orthosis with Two Degrees of Freedom Joint Design on Gait and Sit-to-Stand Task in Patients with Medial Knee Osteoarthritis
}

Siamak Aghajani Fesharaki, ${ }^{1,2}$ Farzam Farahmand, ${ }^{3}$ "Hassan Saeedi, ${ }^{1}$ Seyed Ahmad Raeissadat, ${ }^{4}$ Ehsan Abdollahy, ${ }^{5}$ Amir Ahmadi, ${ }^{6}$ Nader Maroufi ${ }^{6}$

$$
\begin{aligned}
& \text { آثار تقويم الركبة بمغصل ذات درجتين من الحرية على طريقة المشي ومهمة الجلوس } \\
& \text { إلى الوقوف في المرضى الذين يعانون من فصال عظمي إنسي في الركبة }
\end{aligned}
$$$$
\text { سيامك آقانى فشاركي، فرزام فرهمند، حسن سعيدي، سيد أحمد رئيس سادات، إحسان عبد اللهي، أمير أحمدي، نادر معروفي }
$$

ABSTRACT: Objectives: Knee bracing as a conservative treatment option for patients with medial knee osteoarthritis (KOA) is of great interest to health practitioners and patients alike. Optimal orthotic knee joint structure is essential to achieve biomechanical and clinical effectiveness. Therefore, this study aimed to identify the effects of a knee orthosis with a new two-degrees-of-freedom (DOF) joint design on selected gait parameters and in a sit-to-stand task in patients with mild-to-moderate medial KOA. Methods: This study was conducted both at the Physical Medicine and Rehabilitation Clinic in Shahid Modarres Academic Hospital and the Biomechanical Laboratory of Rehabilitation Faculty of Iran University of medical Sciences in Tehran, Iran from September 2015 to October 2017. The gait performance of 16 patients was assessed without an orthosis, using a common one-DOF (DOF) knee orthosis and using the same knee orthosis with a two-DOF orthotic joint design. The interactive shearing force between limb and brace in the shell area during a sit-to-stand test was also identified. Repeated measures analysis of variance was used to analyse the data. Results: Compared with walking with no orthosis, both orthosis conditions reduced the external knee adduction moment significantly $(P \leq 0.05)$. A significant increase between the one-DOF and two-DOF conditions in terms of walking speed $(P=0.041$ and $P=0.009$, respectively) and stride length $(P=0.028$ and $P=0.038$, respectively) was observed. In a sit-to-stand test, wearing the orthosis significantly decreased knee transverse plane range of motion $(P$ $\leq 0.05)$. There was a $41.31 \pm 8.34$ Newtons reduction in knee flexion constraint force. Conclusion: The two-DOF knee orthosis was more comfortable compared to the one-DOF knee orthosis during deep knee flexion. Otherwise, the oneDOF- and two-DOF-braces performed similarly.

Keywords: Knee Osteoarthritis; Orthosis; Braces; Gait Analysis; Rotations; Kinematics; Kinetics; Patient Comfort.

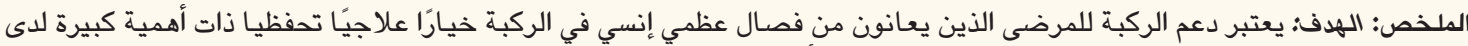

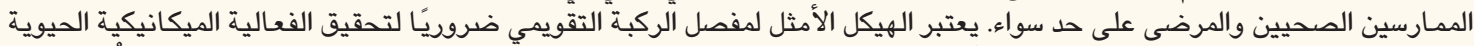

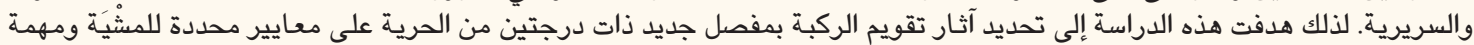

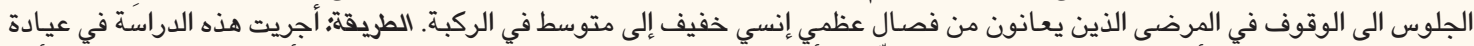

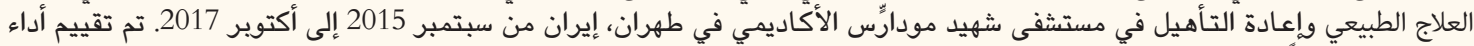

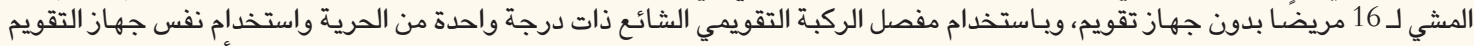

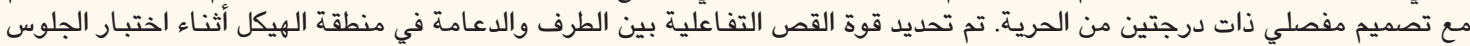

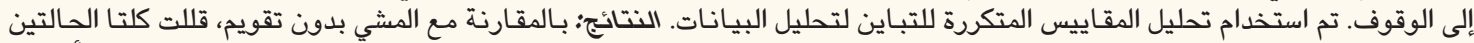

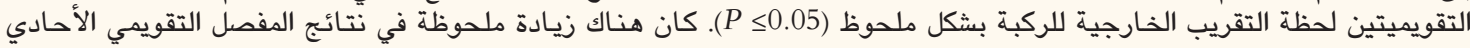
والمفصل التقويمي الثنائي من حيث سرعة التشئي التئي (على التوالي،

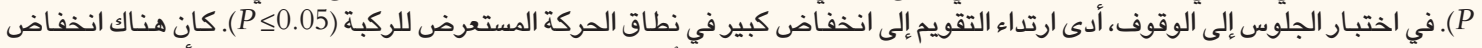

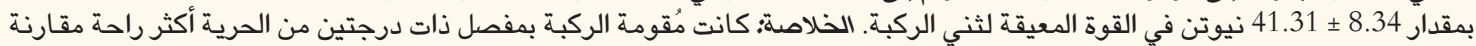

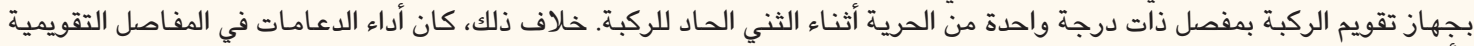
الأحادية والثنائية متماثلا.

$$
\text { الكلمات المفتاحية: فصال عظمي في الركبة؛ تقويم؛ دعامـات؛ تحليل المشي؛ دورات؛ علم الحَرَكات؛ حركيات؛ راحة المريض. }
$$

\section{AdVANCES IN KNOWLEDGE}

Wearing a knee orthosis results in significant improvement in walking parameters in patients with mild-to-moderate medial compartment knee osteoarthritis (KOA).

Departments of ${ }^{1}$ Orthotics \& Prosthetics and ${ }^{6}$ Physiotherapy, School of Rehabilitation Sciences, Iran University of Medical Sciences, Tehran, Iran; ${ }^{2}$ UnderSecretary General for Health, Treatment and Rehabilitation of Iranian Red Crescent Society, Tehran, Iran; ${ }^{3}$ Department of Mechanical Engineering, Sharif University of Technology, Tehran, Iran; ${ }^{4}$ Physical Medicine E Rehabilitation Department, Shahid Modarres Hospital, Shahid Beheshti University of Medical Sciences, Tehran, Iran; ${ }^{5}$ Department of Biomechanics, Djavad Mowafaghian Research Centre of Intelligent Neuro-Rehabilitation Technologies, Tehran, Iran

*Corresponding Author's e-mail: hassan_saeedi2@yahoo.co.uk 
During deep knee flexion, a two-DOF knee orthosis is more comfortable compared to a one-DOF knee orthosis and this finding merits further investigation.

\section{Application to Patient Care:}

This study highlights the possible benefit of adding a transverse plane rotational movement capability in knee orthoses which would be more comfortable for medial KOA patients, especially in sit-to-stand activities where deep flexion is needed.

A

MAJOR AIM OF CONSERVATIVE TREATMENT in patients with knee osteoarthritis (KOA) is to stop or delay the disease progression. ${ }^{1-3}$ One of these conservative modalities, knee braces, is so important that studies have addressed its effects. ${ }^{4,5}$ These braces, regardless of the way they unload the medial compartment of the knee joint or whether they have an orthotic knee joint design, induce a valgus moment to counter the external knee adduction moment (EKAM) applied to the knee during walking. Numerous studies have shown that knee valgus bracing can decrease EKAM and improve overall kinematic and kinetic gait parameters. ${ }^{6-12}$ Although valgus braces have positive effects on knee loading in medial KOA patients, they limit the natural motion of the knee joint in all three planes. ${ }^{13-16}$ Patients who wear knee braces report discomfort, poor fit and skin irritation as the main reasons for discontinuing brace use. ${ }^{17}$ The knee joints in various orthoses are simpler in design and function than anatomic knee joints and may be a reason for these complaints. Because the path of motion in orthotic knee joints does not coincide with that of the natural knee, braces tend to piston over the lower leg limb, leading to limited range of motion (ROM) in the natural knee with subsequent distal migration of the brace and skin discomfort. ${ }^{18,19}$ The lack of freedom in transverse plane motion inside orthotic knee joint structures leads brace wearers to feel uncomfortable while walking, sitting and rising from a chair because of the mismatch between the two joints. Consequently, the natural movement of the knee joint becomes restricted. In addition, a previous study found that the KOA population is prone to torsional misalignment, which is a functional drawback of many knee orthoses. ${ }^{5}$

The current study is based on a previous study that proposed a new two-degrees-of-freedom (DOF) orthotic knee joint design that offers a closer approximation to the natural knee's motion. ${ }^{20}$ The main hypothesis of the current study was that the new orthosis would improve patients' comfort and performance in walking and sit-to-stand activities. It was necessary, however, to conduct a preliminary study in a small sample size to reveal the new brace's effect on walking and sit-to-stand activities before starting with a longitudinal study to distinguish its competency in a larger target group. Therefore, this study aimed to identify the effects of a custom-molded knee orthosis with a novel knee joint on selected temporospatial parameters, kinetics and kinematics of walking and sit-to-stand task in symptomatic individuals with medial KOA. In addition, the study aimed to evaluate the self-assessed comfort of one-DOF and two-DOF orthoses during level walking and sit-to-stand tasks.

\section{Methods}

This study was conducted both at the Physical Medicine and Rehabilitation Clinic in Shahid Modarres Academic Hospital and the biomechanics laboratory of rehabilitation faculty of Iran University of Medical Sciences in Tehran, Iran from September 2015 to October 2017. Participants were recruited from the patient population seeking non-invasive treatment for KOA. Individuals who were $\geq 40$ years old and had been diagnosed with grade II or III medial KOA according to the Kellgren-Lawrence scale were included. Those who had a body mass index (BMI) greater than $35 \mathrm{~kg} / \mathrm{m}^{2}$, the presence of significant pain (including chronic back pain) or other musculoskeletal disorders (for example, ankle, hip or foot disorders), motor neuron disorders, skin problems making it difficult to wear a brace, were not able to understand and perform tasks or had previously had lower-limb surgery were excluded from the study.

The participants visited the biomechanics laboratory twice. In the first session, each patient's lower limb was casted in order to fabricate a customised knee brace. Final brace adjustments were made during the second session. The patients were then asked to perform level walking and sit-to-stand activities with the brace set to one-DOF or two-DOF and without the brace. The order of the two different brace conditions was assigned using a simple randomisation method and the participants had no knowledge of the different orthosis adjustments or what effect to expect. During and immediately after the gait and sit-to-stand analyses, patients were asked to rate the comfort of each brace condition. For integrity, a single researcher was responsible for fitting the knee orthosis to all patients and received training before the study.

Taking into consideration that as a functional drawback of many knee orthoses with only a single 


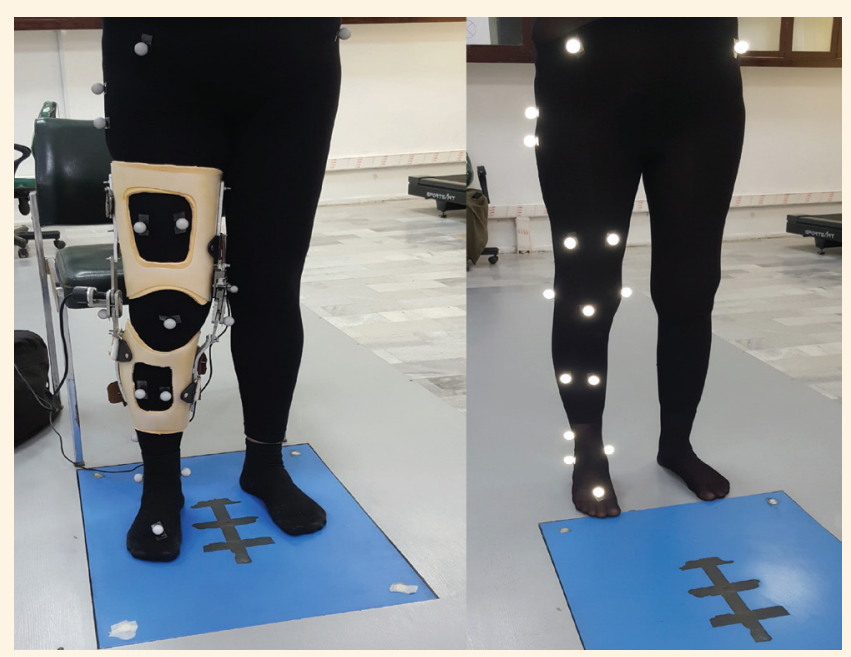

Figure 1: Photographs showing the marker set adopted with the knee orthosis used for three-dimensional gait analysis.
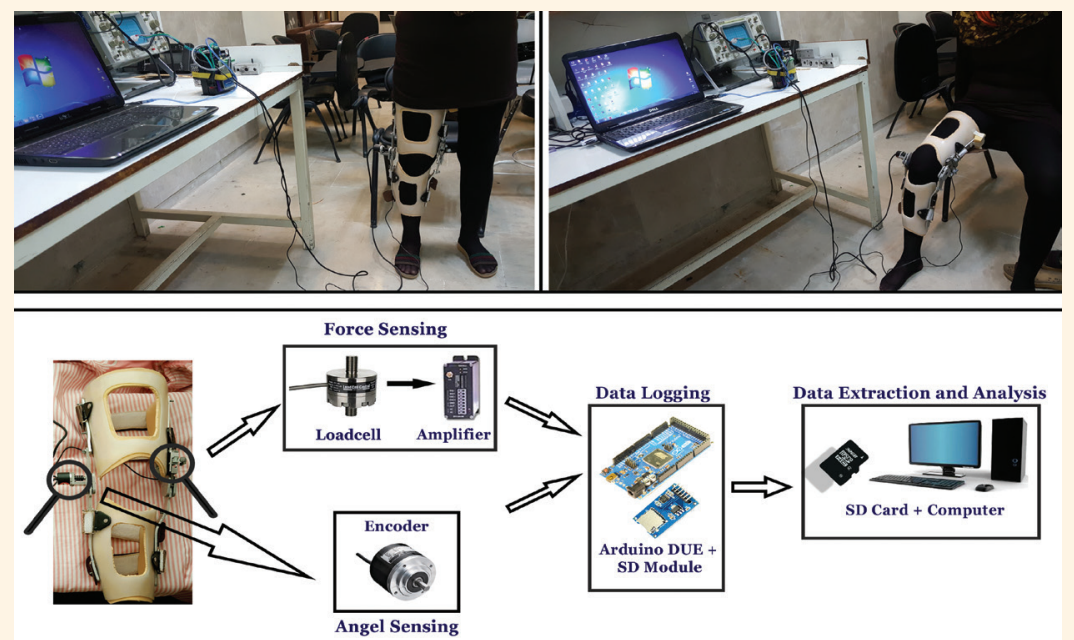

Figure 2: Photographs showing how the interactive shearing force between the limb and the orthosis in a sit-to-stand task was measured using different instruments.

Reproduced and modified from Figure 1 in Aghajani-Fesharaki S, Farahmand F, Saeedi H, Abdollahy E. Design, implementation and testing of a novel prototype orthotic knee joint with two degrees of freedom in a patient with medial knee osteoarthritis. ${ }^{20}$

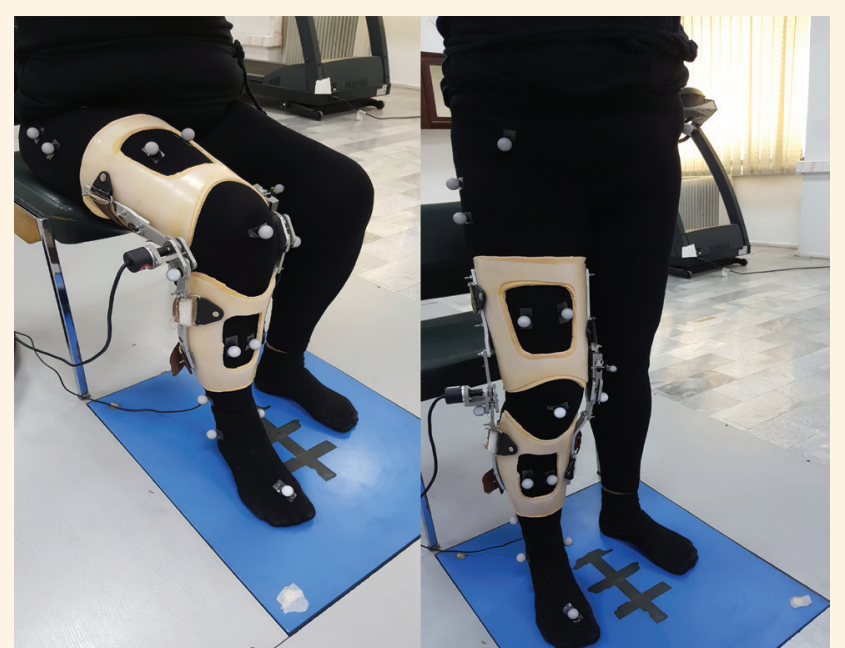

Figure 3: Photographs showing the knee range of motion testing in the transverse plane in a sit-to-stand test with a knee orthosis. 
hinge for OA population in literature which are prone to torsional misalignment ${ }^{5}$, participants were fitted with a bilateral joint type knee orthosis comprised of a new hinge design with two-DOF in the sagittal and transverse planes. This design more closely simulates natural knee joint motion. By unscrewing and detaching the plate, the locked motion in the transverse plane is released and enables the joint to work with two-DOF (i.e. flexion, extension and horizontal rotation). Knee braces were custom-molded through a cast taken by an experienced orthotist while the patients comfortably sat and semi-flexed their knees to ensure the achievement of maximal correction in a valgus position.

Kinematics and kinetics were evaluated using a seven-way camera with a motion capturing system (Qualisys Medical AB, Göteborg, Sweden) operating at $100 \mathrm{~Hz}$ and a piezoelectric force plate (Kistler Instruments AG, Winterthur, Switzerland) operating at $1,000 \mathrm{~Hz}$ embedded on a 10-meter walkway. Before starting data collection during each session, a dynamic and static system calibration was performed. Kinetic and kinematic data synchronisation was obtained using Qualisys Track Manager Software (Qualisys Medical AB). ${ }^{21}$ In total, 17 retro-reflective markers with 14-mm diameters were attached to each participant's skin over anterior superior iliac spines, the greater trochanter, the femur (two over the lower and upper lateral third and two over the anterior of the mid-thigh), the knee's medial and lateral sides, the patella, the tibia (one over the lower lateral third and two over the anterior of the mid-shank), the medial and lateral malleoli, the head of the second metatarsal and the heel. When walking with the knee orthosis, knee markers were attached on the medial and lateral sides of the orthotic knee joint instead [Figure 1].

After familiarisation trials, participants walked at a comfortable self-selected speed along the gait laboratory's walkway. The mean values of three successful trials for each test condition were used for analyses. A trial was considered successful if the participant stepped with the entire foot of the braced side on the force platform. A Woltring filter with a frequency of $10 \mathrm{~Hz}$ was used for data filtering and the time of heel strike was utilised for splitting these data into gait cycle intervals. Participants' lower body anatomy was reconstructed by visual three-dimensional software (C-Motion Research Biomechanics, Germantown, Maryland, USA) to calculate all angles and movements in lower limb joints. EKAM was measured using inverse dynamics and expressed in $\mathrm{Nm} / \mathrm{kg}$. All technical considerations and instrumentations in this task were based on those utilised in a previous study [Figure 2]. ${ }^{20} \mathrm{ROM}$ in the knee's transverse plane was also analysed in the sit-tostand test with participants using the one-DOF and two-DOF braces and without the brace [Figure 3]. All the gait analyses were also performed for the sit-tostand task.

Comfort was assessed on a scale from one (most comfortable) to five (uncomfortable). ${ }^{22}$ Participants walked and completed the sit-to-stand task trials while wearing the orthosis in each of the two brace conditions and provided feedback on their comfort. Participants were blinded to adjustments and brace conditions.

The statistical calculations were carried out using Statistical Package for the Social Sciences (SPSS), Version 22.0 (IBM, Corp., Armonk, New York, USA). All parameters were expressed as mean \pm standard deviation (SD). A Shapiro-Wilk test was used to confirm normal data distribution. Analysis of variance for

Table 1: Kinetic and kinematic parameters during walking and in a sit-to-stand test with a one-degree-of-freedom (DOF) knee orthosis, a two-DOF knee orthosis and without a knee orthosis

\begin{tabular}{|c|c|c|c|}
\hline \multirow[t]{2}{*}{ Variable } & \multicolumn{3}{|c|}{ Mean change $\pm \mathrm{SD}^{*}$} \\
\hline & $\begin{array}{l}\text { Set at one- } \\
\text { DOF }\end{array}$ & $\begin{array}{c}\text { Set at two- } \\
\text { DOF }\end{array}$ & $\begin{array}{l}\text { Without } \\
\text { orthosis }\end{array}$ \\
\hline $\begin{array}{l}\text { Maximum } \\
\text { knee flexion } \\
\text { during stance }\end{array}$ & $14.68 \pm 1.83$ & $15.01 \pm 1.90$ & $16.43 \pm 2.18$ \\
\hline $\begin{array}{l}\text { Maximum } \\
\text { knee } \\
\text { extension } \\
\text { during stance }\end{array}$ & $5.56 \pm 1.38$ & $5.09 \pm 1.33$ & $4.04 \pm 1.17$ \\
\hline $\begin{array}{l}\text { Maximum } \\
\text { knee flexion } \\
\text { during swing }\end{array}$ & $45.83 \pm 5.21$ & $46.80 \pm 4.99^{\dagger}$ & $49.64 \pm 5.19$ \\
\hline $\begin{array}{l}\text { Transverse } \\
\text { plane ROM } \\
\text { during } \\
\text { walking }\end{array}$ & $4.17 \pm 0.56$ & $4.18 \pm 0.56$ & $5.49 \pm 0.61$ \\
\hline $\begin{array}{l}\text { Transverse } \\
\text { plane ROM } \\
\text { during sit-to- } \\
\text { stand test }\end{array}$ & $9.05 \pm 1.23$ & $10.44 \pm 1.19$ & $12.42 \pm 1.1$ \\
\hline $\begin{array}{l}\text { First peak } \\
\text { external knee } \\
\text { adduction } \\
\text { moment in } \\
\mathrm{Nm} / \mathrm{kg}\end{array}$ & $0.568 \pm 0.10$ & $0.568 \pm 0.09$ & $0.637 \pm 0.11$ \\
\hline $\begin{array}{l}\text { Second peak } \\
\text { external knee } \\
\text { adduction } \\
\text { moment in } \\
\mathrm{Nm} / \mathrm{kg}\end{array}$ & $0.607 \pm 0.13$ & $0.606 \pm 0.13$ & $0.673 \pm 0.15$ \\
\hline $\begin{array}{l}S D=\text { standard dev } \\
\mathrm{Nm}=\text { Newton-me } \\
\text { Bonferroni adjuste }\end{array}$ & $\begin{array}{l}\text { on; } D O F=d e \\
\text { Post hoc com } \\
\text { values. }\end{array}$ & $\begin{array}{l}\text { ffreedom; } R O \\
\text { ns between all }\end{array}$ & $\begin{array}{l}\text { range of motion, } \\
\text { conditions with }\end{array}$ \\
\hline
\end{tabular}


repeated measures was used to determine differences between the three conditions. A Bonferroni correction was performed for post hoc pairwise comparisons. $P$ $\leq 0.05$ was considered statistically significant.

Ethical approval was obtained from the Clinical and Research Ethics Committee of the Iran University of Medical Science on 10th February 2015 (\#92-1150-3209). All participants signed an informed consent form before enrolment.

\section{Results}

A total of 16 participants ( $n=11$ women) were included in this study. The majority of the participants were female (68.75\%); the mean \pm SD age, height, weight and BMI were $56.19 \pm 7.61$ years, $1.63 \pm 0.065$ $\mathrm{m}, 73.75 \pm 7.7 \mathrm{~kg}$ and $27.96 \pm 3.22 \mathrm{~kg} / \mathrm{m}^{-2}$, respectively. Seven participants had OA grade II and nine had OA grade III.

Wearing the orthosis in both conditions significantly reduced EKAM $(P \leq 0.001$ each). However, no significant difference was found between the two orthosis conditions $(P>0.05)$.

Table 2: Spatiotemporal parameters during walking with orthoses with one degree of freedom (DOF), two-DOF and without a knee orthosis

\begin{tabular}{lccc} 
Variable & \multicolumn{3}{c}{ Mean \pm SD } \\
& $\begin{array}{c}\text { Set at one- } \\
\text { DOF }\end{array}$ & $\begin{array}{c}\text { Set at two- } \\
\text { DOF }\end{array}$ & $\begin{array}{c}\text { Without } \\
\text { orthosis }\end{array}$ \\
$\begin{array}{l}\text { Walking } \\
\text { speed in } \\
\text { metre/second }\end{array}$ & $0.6 \pm 0.07^{*}$ & $0.63 \pm 0.08^{\dagger}$ & $0.51 \pm 0.09^{* \dagger}$ \\
$\begin{array}{l}\text { Stride length } \\
\text { in metre }\end{array}$ & $0.94 \pm 0.10^{\ddagger}$ & $0.97 \pm 0.11^{\$}$ & $0.84 \pm 0.18^{\ddagger \S}$ \\
$\begin{array}{l}\text { Cadence in } \\
\text { steps/min }\end{array}$ & $76.28 \pm 5.69$ & $77.20 \pm 5.64$ & $73.78 \pm 6.44$ \\
& & &
\end{tabular}

$S D=$ standard deviation; $D O F=$ degree of freedom; min = minute. Post hoc comparisons between all test conditions with Bonferroni adjusted Pvalues.

"Significant difference between conditions without orthosis and orthosis set to one-DOF $(P=0.041)$. ${ }^{\dagger}$ Significant difference bet-

ween conditions without orthosis and orthosis set to two-DOF $(P=0.009)$. ${ }^{7}$ Significant difference between conditions without orthosis and orthosis set to one-DOF $(P=0.028)$. "Significant difference between conditions without orthosis and orthosis set to two-DOF $(P=0.038)$.
Compared to walking without a knee brace, a significant reduction in knee ROM was obtained with both brace conditions $(P \leq 0.01)$. There was also significant difference between brace conditions ( $P$ $\leq 0.01$ ) [Table 1]. Less reduction was found when wearing knee orthosis with two-DoF knee joint.

No significant gait modification was seen in spatiotemporal parameters; however, speed and stride length were modified when wearing the brace. More specifically, wearing the orthosis in both conditions significantly increased walking speed in the one-DOF and two-DOF conditions $(P=0.041$ and $P=0.009$, respectively). Additionally, a significant increase in stride length was measured when wearing the orthosis in the one-DOF and two-DOF conditions $(P=0.028$ and $P=0.038$, respectively). There were no significant differences between the two brace conditions for any spatiotemporal parameters [Table 2].

The sit-to-stand task demonstrated a significant main effect in the knee transverse plane $\operatorname{ROM}(P<0.05)$. A Bonferroni post hoc analysis showed significant differences between all conditions (without orthosis: $12.42 \pm 1.1^{\circ}$; with orthosis set at one-DOF: $9.05 \pm$ $1.23^{\circ}$; with orthosis set at two-DOF: $10.44 \pm 1.19^{\circ}$ ). Comparing the two brace conditions, a significantly lower reduction in the transverse plane was found (19\% versus $35 \%$ decrease; $P \leq 0.01$ ) when participants wore the knee orthosis with two-DOF [Table 1].

When the participants performed the sit-to-stand task while wearing the one-DOF orthosis, the mounted load cell behind the joint detected a load as high as $41.31 \pm 8.34$ Newtons. When the task was repeated with the joint set to two-DOF, the brace was free to mimic more closely the knee joint and, consequently, the knee joint was much more free to flex. Under this condition, participants declared more comfort while seated. The rotary part of the orthotic joint in the transverse plane showed a mean displacement of approximately $1.5 \mathrm{~cm}$ when measuring the movement of the two sliding components when participants started to sit from a standing position and vice versa.

No significant difference was found between walking comfort with orthosis set to one-DOF versus

Table 3: Patient-reported satisfaction score with brace comfort during walking and sit-to-stand test with one-degreeof-freedom (DOF) and two-DOF knee orthoses

\begin{tabular}{lccccc} 
& \multicolumn{3}{c}{ Mean \pm SD } \\
& \multicolumn{2}{c}{ Walking } & \multicolumn{2}{c}{ Sit-to-stand test } \\
Brace comfort satisfaction* & One-DOF & Two-DOF & One-DOF & Two-DOF \\
& $2.44 \pm 0.51$ & $2.37 \pm 0.50$ & $2.37 \pm 0.50^{+}$ & $1.44 \pm 0.50^{+}$
\end{tabular}

$S D=$ standard deviation; $D O F=$ degree of freedom

* Scores ranged from one (most comfortable) to five (uncomfortable). $+P \leq 0.001$ 
two-DOF. However, during the sit-to-stand test, participants reported significantly greater levels of satisfaction of brace comfort when the orthosis was set to two-DOF $(P=0.001)$. A total of 13 from 16 patients (81.25\%) found the knee orthosis with two-DOF to be more comfortable than the knee orthosis with oneDOF (mean satisfaction rate was $1.44 \pm 0.51$ for twoDOF versus $2.37 \pm 0.50$ for one-DOF) [Table 3].

\section{Discussion}

The knee brace utilised in this study produced a corrective force to the knee joint in the coronal plane, reducing EKAM in KOA patients. Previous studies showed that wearing valgus-inducing knee orthoses can result in a reduction in EKAM. ${ }^{8,23,24}$ Although the current study did not aim to compare the effect of wearing a knee orthosis on EKAM, the use of the knee orthosis by KOA patients as a conservative treatment option reduced the effect of the varus moment applied to the knee during walking. This relatively high reduction in EKAM may be due to the type of orthosis used in the study. Custom-made knee orthoses appear more effective at inducing the valgus moment as they fit patients' lower limbs well. ${ }^{4}$

The current study also found that knee braces increased patients' gait speeds due to an increase in stride length. One reason for this result may be that when participants wore their orthoses, their knee joints felt stabilised and subsequently increased their confidence during walking. This finding is in agreement with that of a previous study which proposed wearing knee braces in order to improve knee joint function and stability. ${ }^{25}$ During the stance phase, both knee brace test conditions resulted in greater flexion compared to the no brace condition. During the swing phase, wearing a brace also reduced maximum knee flexion and, as a consequence, the overall knee sagittal plane ROM was reduced. This finding mirrors that of previous studies where knee orthoses reduced overall knee ROM in the sagittal plane. ${ }^{4,23}$ It should be noted that there was a significant difference $(P \leq 0.01)$ in knee ROM between the two brace conditions. The knee orthosis with two-DOF resulted in less reduction in knee ROM during walking. This observation might be due to the lower limitations of movement around the knee joint with the two-DOF brace. Additionally, the two-DOF brace allows the knee to more closely simulate natural motion in the sagittal and transverse planes. This finding of a lower knee ROM with a longer stride length with both orthoses seems to be related to an improvement in the hip joint as an adjacent joint to the knee. Stance phase knee pain with instability is typically seen in KOA patients and they also generally have less ROM of the hip joint during walking.,26 The increased stride length during walking while the patients wore their knee braces not only may have been a result of amelioration of pain and stability in their knee joint but also due to an increase in their hip joint ROM. ${ }^{27}$ Further research focusing on the kinematics of hip and ankle joints will eliminate this ambiguity. In relation to the kinematic changes in knee transverse plane motion with the use of orthosis and their restrictive effects on knee movements have been well documented. ${ }^{21,28,29}$

The sit-to-stand task demonstrated that when the orthotic knee joint transverse DOF was locked (the brace set to the one-DOF condition), the mounted load cell behind the joint detected a mean load of as much as 41 Newtons. The main reason for this load may be due to a mismatch between the orthotic movement pattern and the anatomic joints. In short, the orthosis forces the knee to follow its simplified motions and prevents the rotary part of the natural knee motion to occur. As a result, an unwanted constraint force (interactive shear force) is also generated between the orthosis and the limb in the contact area. This force is transmitted through sidebars into the orthotic joint and measured by the load cell. As the flexion angle increased, the amount of force increased as well. The maximum amount of force was recorded in the last phase of the seated position when the participants flexed their knee joints to approximately $90^{\circ}$. Previous research found that, in case of a mismatch between the kinematics of an orthotic joint and the natural knee, tightening the orthosis will just increase its pistoning force. ${ }^{19}$ The current study's results has confirmed this theory; in addition, a high shearing load was also recorded by the load cell.

When the task was repeated and the orthotic knee joint transverse DOF was released (i.e. two-DOF), the orthotic joint was free to mimic more closely the knee joint and, consequently, the knee joint was much more free to flex. The rotary part of the orthotic joint in the transverse plane showed a mean displacement of approximately $1.5 \mathrm{~cm}$ when measuring the movement of the two sliding components when participants started to sit from a standing position and vice versa.

It is clear that when the knee joint was braced in the two-DOF condition with a lower limitation in the path of its motion, the aforementioned force in the contact area between the orthosis and the limb made the rotary parts of the joint displace and allow the knee joint complete the ROM. To the researchers' best knowledge, little research has evaluated the effect of knee orthoses in sit-to-stand tasks. Therefore, it should be noted that it is difficult to draw definitive conclusions. 
The secondary aim of this study was to investigate patients' comfort levels when walking and in sitto-stand tasks in two orthosis conditions. Patients wearing the two-DOF knee orthosis expressed more comfort when sitting compared with those wearing the one-DOF orthosis, but they did not note differences between these two conditions during level walking. The amount of knee flexion seems to be the main reason for feelings of comfort. In sit-to-stand tests, where deep flexion was needed, the capability of the orthosis with a transverse rotation (i.e. two-DOF) made the patients feel more comfortable. Comfort, however, was rated immediately after wearing the orthosis for only a short time and it is unclear whether this experience provided a true reflection of brace comfort in everyday life. One limitation of this study, therefore, was that only short tests could be performed (e.g. 10 metres of walking). True comfort levels might become evident only after longer brace use. The researchers, however, believe that the two-DOF orthosis might lead to more comfort and better adaptation to daily life based on patients' higher satisfaction with that brace in the laboratory. Additionally, because the one-DOF condition had a lower degree of indicated comfort in laboratory tests, its effectiveness should be further investigated as patients may not be willing to wear this device regularly.

Improved proprioception, that can occur after wearing a knee brace, is a factor that can relieve knee pain. ${ }^{30}$ Pagani et al. observed that knee braces offer mechanical stability to the knee, which could contribute to decreased pathological levels of cocontraction of agonists and antagonists often observed in KOA patients. ${ }^{30}$ Because the intention of the current study was to evaluate that immediate effects of a two-DOF knee orthosis, it was not possible to assess orthosis-related pain levels; this was another limitation of the current study. Longitudinal studies should evaluate this new brace over longer periods of time.

\section{Conclusion}

This study showed that wearing knee orthoses improved KOA patients' gait parameters. The novel knee orthosis with degrees of freedom in the sagittal and transverse planes offered slightly more comfort when moving from sitting to standing, which could result in better compliance with bracing. Furthermore, both knee orthoses unloaded medial compartments, suggesting benefits for patients with medial KOA. Additionally, patients may experience greater comfort while sitting when using a brace with a two-DOF hinge instead of a one-DOF hinge. However, the effects of this orthosis on daily wear and long-term compliance needs to be confirmed by further studies.

\section{CONFLICT OF INTEREST}

The authors declare no conflicts of interest.

\section{FUNDING}

No funding was received for this study.

\section{References}

1. van Raaij TM, Reijman M, Brouwer RW, Bierma-Zeinstra SM, Verhaar JA. Medial knee osteoarthritis treated by insoles or braces: A randomized trial. Clin Orthop Relat Res 2010; 468:1926-32. https://doi.org/10.1007/s11999-010-1274-z.

2. Jones RK, Nester CJ, Richards JD, Kim WY, Johnson DS, Jari S, et al. A comparison of the biomechanical effects of valgus knee braces and lateral wedged insoles in patients with knee osteoarthritis. Gait Posture 2013; 37:368-72. https://doi.org/10.10 16/j.gaitpost.2012.08.002

3. Raja K, Dewan N. Efficacy of knee braces and foot orthoses in conservative management of knee osteoarthritis: A systematic review. Am J Phys Med Rehabil 2011; 90:247-62. https://doi. org/10.1097/PHM.0b013e318206386b.

4. Hunter D, Gross KD, McCree P, Li L, Hirko K, Harvey WF. Realignment treatment for medial tibiofemoral osteoarthritis: Randomised trial. Ann Rheum Dis 2012; 71:1658-65. https:// doi.org/10.1136/annrheumdis-2011-200728.

5. Fantini Pagani CH, Hinrichs M, Brüggemann GP. Kinetic and kinematic changes with the use of valgus knee brace and lateral wedge insoles in patients with medial knee osteoarthritis. J Orthop Res 2012; 30:1125-32. https://doi.org/10.1002/jor.22032.

6. Dessery Y, Belzile EL, Turmel S, Corbeil P. Comparison of three knee braces in the treatment of medial knee osteoarthritis. Knee 2014; 21:1107-14. https://doi.org/10.1016/j.knee.2014.07.024.

7. Schmalz T, Knopf E, Drewitz H, Blumentritt S. Analysis of biomechanical effectiveness of valgus-inducing knee brace for osteoarthritis of the knee. J Rehabil Res Dev 2010; 47:419-29. https://doi.org/10.1682/JRRD.2009.05.0067.

8. Della Croce U, Crapanzano F, Li L, Kasi PK, Patritti BL, Mancinelli C, et al. A preliminary assessment of a novel pneumatic unloading knee brace on the gait mechanics of patients with knee osteoarthritis. PM R 2013; 5:816-24. https://doi.org/10.1016/j.pmrj.2 013.06.008.

9. Johnson AJ, Starr R, Kapadia BH, Bhave A, Mont MA. Gait and clinical improvements with a novel knee brace for knee OA. J Knee Surg 2013; 26:173-8. https://doi.org/10.1055/s-003 $2-1327452$.

10. Moyer RF, Birmingham TB, Bryant DM, Giffin JR, Marriott KA, Leitch KM. Biomechanical effects of valgus knee bracing: A systematic review and meta-analysis. Osteoarthritis Cartilage 2015; 23:178-88. https://doi.org/10.1016/j.joca.2014.11.018.

11. Iijima $\mathrm{H}$, Isho $\mathrm{T}$, Aoyama T. Effects of knee orthoses on walking capacity and biomechanics in patients with knee osteoarthritis: A critical review. OA Musculosk Med 2014; 2:13.

12. Laroche D, Morisset C, Fortunet C, Gremeaux V, Maillefert JF, Ornetti P. Biomechanical effectiveness of a distraction-rotation knee brace in medial knee osteoarthritis: Preliminary results. Knee 2014; 21:710-16. https://doi.org/10.1016/j.knee.2014.02.015.

13. Hanzlíková I, Richards J, Hébert-Losier K, Smékal D. The effect of proprioceptive knee bracing on knee stability after anterior cruciate ligament reconstruction. Gait Posture 2019; 67:242-7. https://doi.org/10.1016/j.gaitpost.2018.10.026. 
14. Théoret D, Lamontagne M. Study on three-dimensional kinematics and electromyography of ACL deficient knee subjects wearing a functional knee brace during running. Knee Surg Sports Traumatol Arthrosc 2006; 14:555-63. https://doi.org/10.1007/ s00167-006-0072-3.

15. Singer JC, Lamontagne $M$. The effect of functional knee brace design and hinge misalignment on lower limb joint mechanics. Clin Biomech (Bristol, Avon) 2008; 23:52-9. https://doi.org/10.10 16/j.clinbiomech.2007.08.013

16. Hanzlíková I, Richards J, Tomsa M, Chohan A, May K, Smékal D, et al. The effect of proprioceptive knee bracing on knee stability during three different sport related movement tasks in healthy subjects and the implications to the management of anterior cruciate ligament (ACL) injuries. Gait Posture 2016; 48:165-70. https://doi.org/10.1016/j.gaitpost.2016.05.011.

17. Squyer E, Stamper DL, Hamilton DT, Sabin JA, Leopold SS Unloader knee braces for osteoarthritis: Do patients actually wear them? Clin Orthop Relat Res 2013; 47:1982-91. https:// doi.org/10.1007/s11999-013-2814-0.

18. Lew WD, Patrnchak CM, Lewis JL, Schmidt J. A comparison of pistoning forces in orthotic knee joints. Orthot Prosthet 1982; 36:85-95.

19. Lewis GL, Lew WD, Patrnchak CM, Shybut GT. A new concept in orthotics joint design-The Northwestern University Knee Orthosis System. Orthot Prosthet 1983; 37:15-23.

20. Aghajani-Fesharaki S, Farahmand F, Saeedi H, Abdollahy E. Design, implementation and testing of a novel prototype orthotic knee joint with two degrees of freedom in a patient with medial knee osteoarthritis. Sultan Qaboos Univ Med J 2018; 18:524-8. https://doi.org/10.18295/squmj.2018.18.04.016.

21. Sinclair JK, Vincent H, Richards JD. Effects of prophylactic knee bracing on knee joint kinetics and kinematics during netball specific movements. Phys Ther Sport 2017; 23:93-8. https:// doi.org/10.1016/j.ptsp.2016.08.005.

22. Mauricio E, Sliepen M, Rosenbaum D. Acute effects of different orthotic interventions on knee loading parameters in knee osteoarthritis patients with varus malalignment. Knee 2018; 25: 825-33. https://doi.org/10.1016/j.knee.2018.06.017.
23. Jones RK, Nester CJ, Richards JD, Kim WY, Johnson DS, Jari S, et al. A comparison of the biomechanical effects of valgus knee braces and lateral wedged insoles in patients with knee osteoarthritis. Gait Posture 2013; 37:368-72. https://doi.org/10.1 016/j.gaitpost.2012.08.002.

24. Fantini Pagani CH, Potthast W, Brüggemann GP. The effect of valgus bracing on the knee adduction moment during gait and running in male subjects with varus alignment. Clin Biomech (Bristol,Avon) 2010;25:70-6.https://doi.org/10.1016/j.clinbiom ech.2009.08.010

25. Ramsey DK, Briem K, Axe MJ. A mechanical theory for the effectiveness of bracing for medial compartment osteoarthritis of the knee. J Bone Joint Surg Am 2007; 89:2398-407. https:// doi.org/10.2106/JBJS.F.01136

26. Al-Zahrani KS, Bakheit AM. A study of the gait characteristics of patients with chronic osteoarthritis of the knee. Disabil Rehabil 2002; 24:275-80. https://doi.org/10.1080/09638280110087098.

27. Arazpour M, Hutchins SW, Bani MA, Curran S, Aksenov A. The influence of a bespoke unloader knee brace on gait in medial compartment osteoarthritis: A pilot study. Prosthet Orthot Int 2014; 38:379-86. https://doi.org/10.1177/0309364613504780.

28. Jalali M, Farahmand F, Esfandiarpour F, Golestanha SA, Akbar M, Eskandari A, et al. The effect of functional bracing on the arthrokinematics of anterior cruciate ligament injured knees during lunge exercise. Gait Posture 2018; 63:52-7. https://doi. org/10.1016/j.gaitpost.2018.04.022.

29. Kwaees TA, Richards J, Rawlinson G, Charalambous CP, Chohan A. Can the use of proprioceptive knee braces have implications in the management of osteoarthritic knees: An exploratory study. Prosthet Orthot Int 2019; 43:140-7. https:// doi.org/10.1177/0309364618796852.

30. Fantini Pagani $\mathrm{CH}$, Willwacher S, Kleis B, Brüggemann GP. Influence of a valgus knee brace on muscle activation and co-contraction in patients with medial knee osteoarthritis. J Electromyogr Kinesiol 2013; 23:490-500. https://doi.org/10.10 16/j.jelekin.2012.10.007. 